\title{
Comparison of Lewis Acidity between Al-MCM-41 Pure Chemicals and Al-MCM-41 Synthesized from Bentonite
}

\author{
Tewfik Ali-Dahmane ${ }^{1,2^{*}}$, Lamia Brahmi ${ }^{3,4}$, Rachida Hamacha ${ }^{1}$, Salih Hacini ${ }^{3}$, \\ Abdelkader Bengueddach ${ }^{1}$ \\ ${ }^{1}$ Laboratoire de Chimie des Matériaux L.C.M, Université Oran1, BP-1524 El-Mnaouer, \\ 31000 Oran, Algeria \\ ${ }^{2}$ École Supérieure en Sciences Appliquées de Tlemcen (ESSAT), BP 165 RP Bel horizon, \\ 13000 Tlemcen, Algeria \\ ${ }^{3}$ Laboratoire de Chimie fine L.C.F., Université Oran1, BP-1524 El-Mnaouer, \\ 31000 Oran, Algeria \\ ${ }_{4}^{4}$ Université A Belkaid, B.P 119, 22 rue Abi Ayad Abdelkrim, Fg Pasteur, \\ 13000 Tlemcen, Algeria
}

Received: $13^{\text {rd }}$ August 2018; Revised: 14 $4^{\text {th }}$ January 2019; Accepted: $1^{\text {st }}$ February 2019; Available online: 30th April 2019; Published regularly: 1st August 2019

\section{Abstract}

This study focused on the Lewis acidity of Al-MCM-41 prepared from bentonite (Al-MCM-bentonite) as silica and aluminum source simultaneously. This acidity was compared with Al-MCM-41 synthesized from pure chemicals reagents (Al-MCM-standard). Structural analysis showed that the substitution of the silicon atom by the aluminum atom decreases the structural order of Al-MCM-standard, whereas Al-MCM-bentonite has a better structural organization. The Lewis acidity of the Al-MCM-bentonite was evaluated in allylation reaction of benzaldehyde with allyltrimethylsilane and pyridine adsorption experiments. The results showed that the difference in acidity between Al-MCM-standard and Al-MCM-bentonite is due to the amount of aluminum incorporated into the framework of our mesoporous materials. According to the EDX analysis, the incorporation of aluminum in Al-MCM-standard $(\mathrm{Si} / \mathrm{Al}=13.47)$ is more important than in $\mathrm{Al}-\mathrm{MCM}$-bentonite $(\mathrm{Si} / \mathrm{Al}=43.64)$. This explains the low acidity of Al-MCM-bentonite, and the moderate yields in the allylation reactions of benzaldehyde with allyltrimethylsilane. Copyright (c) 2019 BCREC Group. All rights reserved

Keywords: Mesoporous materials; Al-MCM-41; Algerian bentonite; Lewis acid; Allylation of benzaldehyde

How to Cite: Ali-Dahmane, T., Brahmi, L., Hamacha, R., Hacini, S., Bengueddach, A. (2019). Comparison of Lewis Acidity between Al-MCM-41 Pure Chemicals and Al-MCM-41 Synthesized from Bentonite. Bulletin of Chemical Reaction Engineering \& Catalysis, 14(2): 358-368 (doi:10.9767/bcrec.14.2.3367.358-368)

Permalink/DOI: https://doi.org/10.9767/bcrec.14.2.3367.358-368

\section{Introduction}

Many organic syntheses require catalytic reactions involving homogeneous Lewis acid, such

* Corresponding Author.

E-mail: byalidahmane@gmail.com (T. Ali-Dahman);

Telp: +213-661220618, Fax: +213-661220618 as: $\mathrm{BF}_{3}[1], \quad \mathrm{Sc}\left(\mathrm{OTf}_{3}\right)$ [2], $\mathrm{InCl}_{3}[3], \mathrm{YbCl}_{3}$ [4], $\mathrm{FeCl}_{3}[5]$, and $\mathrm{TiCl}_{4}[6,7]$. The challenge for this type of reaction is to replace these homogeneous acids by heterogeneous acids which are environmentally benign catalysts, such as: MCM-41 mesoporous materials, which is the best known member of the family of materials called M41S $[8,9]$. This material has a uniform pore size dis- 
tribution in the mesopore range tunable between $20 \AA$ and $100 \AA$, a high specific surface area of up to $1500 \mathrm{~m}^{2} / \mathrm{g}$, and a high porosity, which is of the order of $\left(1.2 \mathrm{~cm}^{3} / \mathrm{g}\right)$.

The synthesis of MCM-41 requires very reactive starting reagents such as silicate sources and aluminum sources [10-14]. In recent years and for economical and environmental considerations, researchers have being studying the possibility of replacing these laboratory reagents with raw materials that are widely available and inexpensive. Therefore, studies have reported the synthesis of mesoporous materials from halloysite [15], diatomite [16], kaolin [17], bentonite [18,19], coal fly ash [20], bottom ash [21,22], iron-ore tailing [23], copper-ore tailing [24], photonic waste [25,26], resin ash [27], husk ash [28,29], sedge ash [30], miscanthus ash [31], and volclay [32].

The use of bentonite as a silica and aluminum source for the preparation of mesoporous materials is very rare in the literature, and has been studied $[18,19]$. In this work, we focus on the study of the Lewis acidity of Al-MCM-41 synthesized from bentonite (Al-MCMbentonite). The Lewis acidity of aluminumcontaining MCM-bentonite was evaluated using allylation reaction of aromatic aldehydes with allyltrimethylsilane and this acidity was compared with that of the material prepared by laboratory reagents (Al-MCM-standard). We studied a number of parameters, namely the effect of temperature and the effect of amount of the catalyst $(X \mathrm{~mol} \%)$.

\section{Materials and Methods}

\subsection{Materials}

The natural bentonite used in this study was obtained from Maghnia mine (Hammam Boughrara, $600 \mathrm{~km}$ west of the capital Algiers) and used as obtained. The other reactants applied were cetyltrimethylammonium bromide $\left(\mathrm{C}_{19} \mathrm{H}_{42} \mathrm{NBr}\right.$; CTAB, Merck, 99\%), ammonium hydroxide $\left(\mathrm{NH}_{3}\right.$, Aldrich, $\left.25 \%\right)$, acetic acid (min. 99.8\%, Aldrich), sodium aluminate (54\% $\mathrm{Al}_{2} \mathrm{O}_{3} ; 41 \% \mathrm{Na}_{2} \mathrm{O} ; 5 \% \mathrm{H}_{2} \mathrm{O}$, Aldrich), colloidal silica (ludox 40\%, Prolabo), and tetramethylammonium hydroxide (TMAOH. $5 \mathrm{H}_{2} \mathrm{O}$, $97 \%$, Aldrich).

\subsection{Synthesis of Al-MCM-bentonite}

The synthesis of Al-MCM-bentonite material evaluated in this work was previously reported [19]. The preparation of Al-MCM-41 from Algerian bentonite requires the following steps; firstly the alkaline melting of the bentonite, in this step the mixture of bentonite and sodium hydroxide was prepared (using a weight ratio betonite/NaOH $=1 / 1.2$ ), and then calcined at $550{ }^{\circ} \mathrm{C}$ in air for 1 hour. The obtained solid was cooled at room temperature and then milled. An amount of water was added to the resultant material such that the weight ratio bentonite/water was $1 / 4$. The mixture was stirred for $24 \mathrm{~h}$ at room temperature and then the supernatant was recovered by centrifugation.

The second step requires the preparation of a solution containing $15 \mathrm{~mL}$ of distilled water, $\mathrm{NH}_{4} \mathrm{OH}(0.75 \mathrm{~g})$ and $0.867 \mathrm{~g}$ of $\mathrm{CTABr}$ which were mixed with $40 \mathrm{~mL}$ of supernatant (obtained in the first step). The $\mathrm{pH}$ of the mixture was adjusted with acetic acid (1 M) until $\mathrm{pH}=9.5$ followed by stirring for $1 \mathrm{~h}$ at room temperature and then hydrothermally treated at $100{ }^{\circ} \mathrm{C}$ for 48 hours. The final product was filtered washed, dried for 24 hours at $100{ }^{\circ} \mathrm{C}$ and calcined at $550{ }^{\circ} \mathrm{C}$ for 12 hours. The resulting material was named Al-MCM-bentonite.

\subsection{Synthesis of MCM-standard}

The synthesis and characterization the Sior Al-MCM-standard, were given elsewhere [7,33]. The molar chemical composition used was: $\mathrm{SiO}_{2}: 0.25 \mathrm{CTAB}: 0.2 \mathrm{TMAOH}: 0.04$ $\mathrm{Al}_{2} \mathrm{O}_{3}: 40 \mathrm{H}_{2} \mathrm{O}$. The mesoporous material AlMCM-41 was synthesized by hydrothermal route. Firstly, three solutions were prepared, the first solution containing distilled water, TMAOH and sodium aluminate. The second solution contains only distilled water and colloidal silica. Both solutions were added dropwisely into the third solution containing distilled water and $\mathrm{CTABr}$, the reaction mixture was stirred vigorously for 1 hour at room temperature. The mixture was transferred to an autoclave and then hydrothermally treated at 100 ${ }^{\circ} \mathrm{C}$ for 48 hours. The product was filtered washed and dried for 48 hours at $100{ }^{\circ} \mathrm{C}$ and then calcined in air for 12 hours at $550{ }^{\circ} \mathrm{C}$. The obtained material was named Al-MCMstandard.

The mesoporous silica Si-MCM-41 was obtained according to the following steps; firstly, the surfactant $\mathrm{CTABr}$ was mixed with a solution containing distilled water and TMAOH. After stirring for $30 \mathrm{~min}$, ludox as silica source was added dropwisely and stirred for 2 hours at room temperature. This mixture was hydrothermally treated at $100^{\circ} \mathrm{C}$ for 48 hours. Finally, the obtained product was washed dried at $100{ }^{\circ} \mathrm{C}$ for 24 hours and then calcined at $550{ }^{\circ} \mathrm{C}$ 
during 12 hours. The final product was named Si-MCM-standard.

\subsection{Samples Characterization}

The mesoporous materials were characterized by powder X-ray Diffraction (XRD, Bruker D5005 diffractometer, $\mathrm{Cu}-\mathrm{K} \alpha$ radiation $(\lambda=$ $1.15406 \AA$ ) , scanning step $0.0358^{\circ}$ between $1^{\circ}$ and $10^{\circ}(2 \theta)$ ), $\mathrm{N}_{2}$ gas sorption (Nova 1000e, the
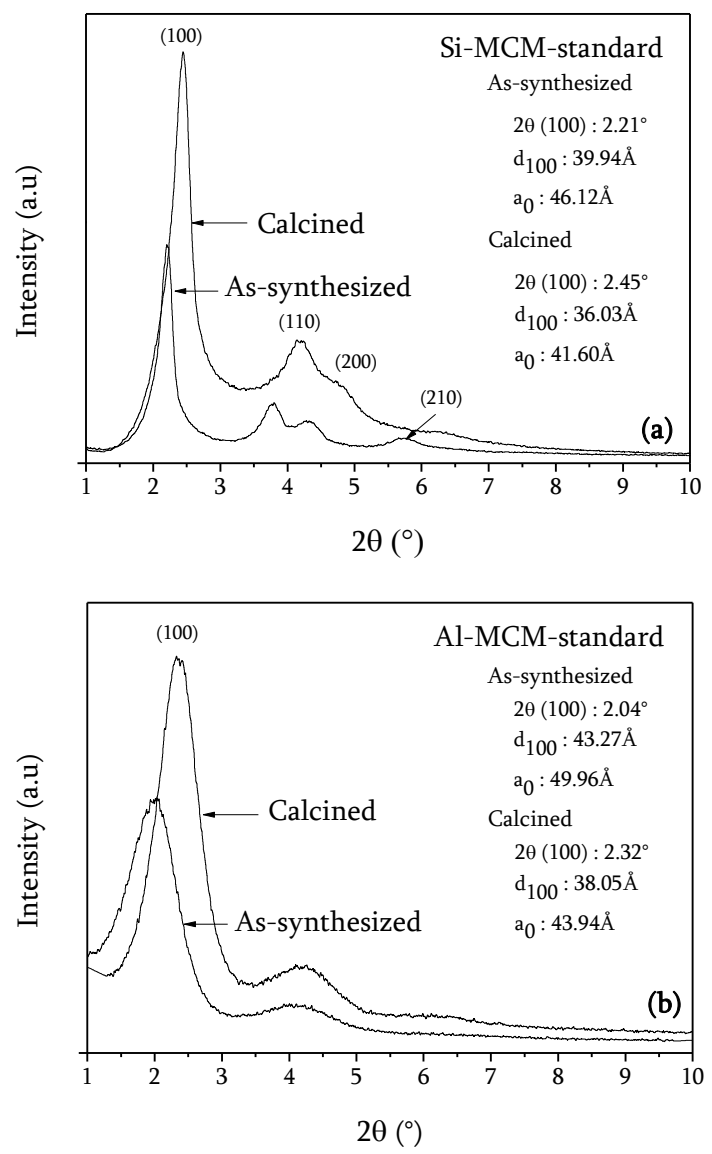

measurements were performed at $-196{ }^{\circ} \mathrm{C}$, the sample was degassed under vacuum at $200{ }^{\circ} \mathrm{C}$ over 24 hours prior to adsorption, the specific surface area was determined by using the BET method [34] from data in a relative pressure range from 0.04 to 0.2 ). The local chemical composition of the mesoporous aluminosilicates was examined by analytical Transmission Electron Microscopy (TEM) combined with an Energy Dispersive X-ray spectroscopy (EDX), (Philips ESEM XL 30 FEG), and the acid properties of the solid were measured using Nicolet Avartar 360 with pyridine adsorption / desorption (FT-IR spectra were then recorded at different temperature: 50, 150, 250, and 350 $\left.{ }^{\circ} \mathrm{C}\right)$.

\subsection{Catalytic Performance}

The procedure experimental of allylation of benzaldehyde with allyltrimethylsilane has been described in detail in our previous work [7]. The catalysts (Al-MCM-bentonite or AlMCM-standard) were dried under vacuum at

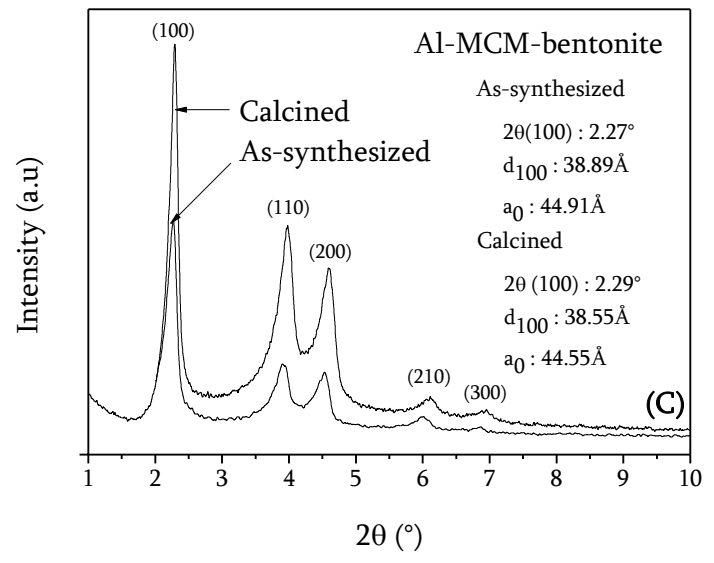

Figure 1. XRD patterns of Si-MCM-standard (a), Al-MCM-standard (b) and Al-MCM-bentonite (c)

Table 1. XRD diffraction results

\begin{tabular}{|c|c|c|c|c|c|c|c|c|c|}
\hline \multirow[b]{2}{*}{ Sample } & \multicolumn{4}{|c|}{ As-synthesized } & \multicolumn{4}{|c|}{ Calcined } & \multirow{2}{*}{$\begin{array}{r}\Delta a_{0} \mathrm{~d} \\
(\%)\end{array}$} \\
\hline & $\begin{array}{l}I_{100^{\mathrm{a}}} \\
\text { (a.u.) }\end{array}$ & $\begin{array}{c}2 \theta \\
(100) \\
\end{array}$ & $\begin{array}{l}d_{100^{\mathrm{b}}} \\
(\AA)\end{array}$ & $\begin{array}{l}a_{o^{\mathrm{c}}} \\
(\AA) \\
(\AA)\end{array}$ & $\begin{array}{l}I_{100} \\
\text { (a.u.) }\end{array}$ & $\begin{array}{c}2 \theta \\
(100) \\
\end{array}$ & $\begin{array}{l}d_{100} \\
(\AA)\end{array}$ & $\begin{array}{l}a_{0} \\
(\AA)\end{array}$ & \\
\hline $\begin{array}{l}\text { Al-MCM- } 41 \\
\text { from bentonite }\end{array}$ & 5369 & 2.27 & 38.89 & 44.91 & 9359 & 2.29 & 38.55 & 44.51 & 0.9 \\
\hline $\begin{array}{l}\text { Al-MCM- } 41 \\
\text { stantard }\end{array}$ & 5994 & 2.04 & 43.27 & 49.96 & 9276 & 2.32 & 38.05 & 43.94 & 12.0 \\
\hline $\begin{array}{l}\text { Si-MCM- } 41 \\
\text { standard }\end{array}$ & 13645 & 2.21 & 39.94 & 46.12 & 25718 & 2.45 & 36.03 & 41.60 & 9.8 \\
\hline
\end{tabular}

a Intensity of the reflection peak (100).

b XRD (100) interplanar spacing, $n \lambda=2 d_{100} \sin \theta$.

c Unit cell determined for a hexagonal symmetry, $a_{0}=2 d_{100} / \sqrt{ } 3$.

d $D a_{0}(\%)=\left(\left[a_{0}(\right.\right.$ as-synthesized $)-a_{0}($ calcined $\left.)\right] / a_{0}($ as-synthesized $\left.)\right) \times 100$. 
$300{ }^{\circ} \mathrm{C}$ for 1 hour prior to the catalytic test. Approximately, $0.106 \mathrm{~g}(1 \mathrm{mmol})$ of benzaldehyde, $2 \mathrm{~mL}$ of dichloromethane and $25 \mathrm{~mol} \%$ of catalyst was added in a two-necked flask under an argon atmosphere. After 5 min of stirring at 35 ${ }^{\circ} \mathrm{C}$, the solution containing allyltrimethylsilane (0.228 g, $2 \mathrm{mmol}, 2$ equiv) and $\mathrm{CH}_{2} \mathrm{Cl}_{2}(0.5 \mathrm{~mL})$ was slowly added under constant temperature $\left(35{ }^{\circ} \mathrm{C}\right)$ and the reaction product was followed by TLC. At the end of the reaction the catalyst was separated by a simple filtration. The filtrate was purified by silica-gel column chromatography using petroleum ether:ether of 28:1. The obtained product was characterized by ${ }^{1} \mathrm{HNMR}$ and ${ }^{13} \mathrm{CNMR}$.

\section{Results and Discussion}

\subsection{Structural Discussion of Catalyst}

The isomorphic substitution of the silicon atom by the aluminum atom $(\mathrm{Si} / \mathrm{Al}=12.5)$ (Figure $1 \mathrm{~b}$ and Table 1) decreases the structural order of Al-MCM- standard, compared with Si-MCM-standard. In the Al-MCM-standard, the reflection peaks (110) and (200) observed in Si-MCM-41 were not well developed, indicating more disordered arrangement of channels for the Al-MCM-standard, however an hexagonal structure with good regularity was kept. It has already been proved that the introduction of an heteroatom affect the structural order of mesoporous solids and more the aluminium content is high more the structural effect is high [35]. In contrast, the synthesis of Al-MCM-bentonite from the dissolution of the silicon and aluminum species that exist in bentonite using the fusion method provides a well-ordered mesoporous material with hexagonal regularity characterized by better resolved of the peaks (110), (200), (210), and (300).

Table 1 shows that the contraction of the unit cell $\left(\Delta a_{0}=0.9 \%\right)$ and the enlargement of the peak (100) of Al-MCM-bentonite are negligible after calcination at $550{ }^{\circ} \mathrm{C}$ for six hours. The presence of the diffraction peak (300) indicates that the high hexagonal uniformity is maintained after calcinations (Figure 1c).

Figure 2 shows the $\mathrm{N}_{2}$ adsorptiondesorption isotherms of the calcined Si-, AlMCM-standard, and Al-MCM-bentonite, and Table 2 summarizes the textural proprieties of theses samples. The obtained isotherms are typical for MCM-41 phase. The corresponding isotherm is of type IV, characteristic of the mesoporous solids according to the IUPAC nomenclature. The Table 2 clearly illustrates that
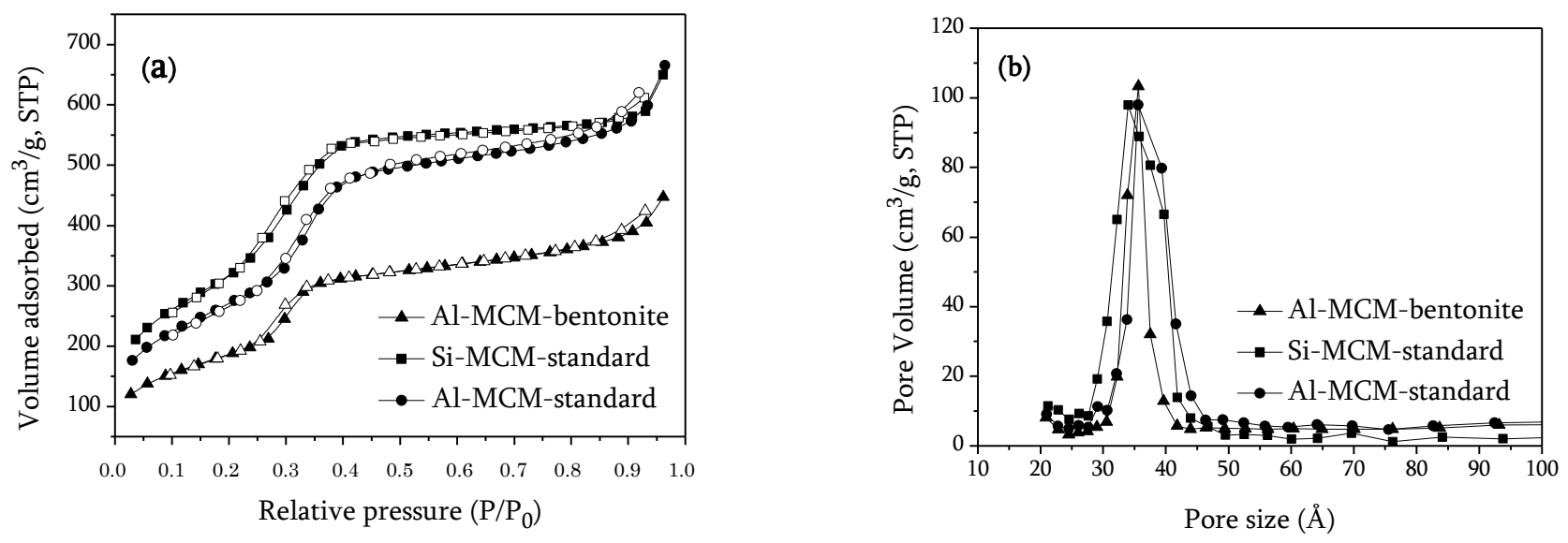

Figure 2. (a) Nitrogen adsorption-desorption isotherms of calcined samples and (b) BJH pore size distribution

Table 2. Textural properties of the samples

\begin{tabular}{lcccccc}
\hline \multicolumn{1}{c}{ Sample } & $\begin{array}{c}a_{0} \\
(\AA)\end{array}$ & $\begin{array}{c}\Delta a_{0} \\
(\%)\end{array}$ & $\begin{array}{c}S_{B E T^{\mathrm{a}}} \\
\left(\mathrm{m}^{2} / \mathrm{g}\right)\end{array}$ & $\begin{array}{c}V_{\text {meso }}{ }^{\mathrm{b}} \\
\left(\mathrm{cm}^{3} / \mathrm{g}\right)\end{array}$ & $\begin{array}{c}D_{p^{\mathrm{c}}} \\
(\AA)\end{array}$ & $\begin{array}{c}W_{t^{\mathrm{d}}} \\
(\AA)\end{array}$ \\
\hline Al-MCM- bentonite & 44.51 & 0.9 & 674 & 0.42 & 35.6 & 8.9 \\
Al-MCM-standard & 43.94 & 12.0 & 983 & 0.76 & 35.6 & 8.4 \\
Si-MCM-standard & 41.60 & 9.8 & 1154 & 0.84 & 34.0 & 7.6 \\
\hline
\end{tabular}

a Specific surface area.; ${ }^{\mathrm{b}}$ Mesoporous volume.; c Pore diameter determined by BJH.; d Wall thikness, $a_{0}-D_{p}$. 
the incorporation of aluminum species in the mesoporous framework affects the structure and the texture of these materials. The pore diameter and the wall thickness of Al-MCMstandard and Al-MCM-bentonite are higher than Si-MCM-standard. This can be explained by the incorporation of aluminum species [36]. On the other hand, the pore volume together with the BET surface area decreased for AlMCM-standard and Al-MCM-bentonite, which suggested generally that heteroatoms incorporation would result in a shift to higher pore size and decrease in specific surface areas [37].

The structural and textural comparison of Al-MCM-standard and bentonite derived AlMCM-41 compared to pure silica MCM-41 showed that the incorporation of aluminum species decreases the structural order of $\mathrm{Al}$ MCM-standard, whereas Al-MCM-bentonite has better structural organization. However, this interesting structural order of Al-MCMbentonite does not reflect its textural properties: $S_{\text {BET of }} 674 \mathrm{~m}^{2} / \mathrm{g}$ and mesoporous volume of $0.42 \mathrm{~cm}^{3} / \mathrm{g}$, compared to those of Al-MCMstandard ( $S_{\text {BET }}$ of $983 \mathrm{~m}^{2} / \mathrm{g}$ and mesoporous volume of $0.76 \mathrm{~cm}^{3} / \mathrm{g}$ ). This confirms the utility of the characterizing of X-ray diffraction and nitrogen adsorption at $77 \mathrm{~K}$ jointly.
3.2. Allylation of Aromatic Aldehydes with Allyltrimethylsilane in the Presence of Al-MCMbentonite or Al-MCM-standard

In our previous work [7], the catalytic performance of Al-MCM-41 prepared from pure chemicals was tested as a Lewis acid in the allylation of aromatic aldehydes with allyltrimethylsilane. The results showed that homoallyl silyl ether is obtained at a temperature of 35 ${ }^{\circ} \mathrm{C}$. In this work, the Lewis acidity of the AlMCM-41 prepared from bentonite was further evaluated using allylation of aromatic aldehydes with allyltrimethylsilane reaction and compared with Al-MCM-41 pure chemicals. We have studied a number of parameters, namely the effect of temperature and the effect of amount of the catalyst ( $X \mathrm{~mol} \%)$.

\subsubsection{Effect of reaction temperature}

In order to study the effect of reaction temperature, we have used the same conditions of previous work [7]. Table 3 depicts the results using MCM-bentonite or Al-MCM-standard as catalysts Lewis acid. By reaction of benzaldehyde (1 equiv) with allyltrimethylsilane (3 equiv), using a catalytic amount $(25 \mathrm{~mol} \%)$ of MCM-bentonite or Al-MCM-standard, and at low temperature $\left(-85^{\circ} \mathrm{C}\right.$ to $\left.10{ }^{\circ} \mathrm{C}\right)$, the condensation reaction does not give any product

Table 3. Allylation of aromatic aldehydes with allyltrimethylsilane: effect of reaction temperature in the presence of Al-MCM-bentonite or Al-MCM-standard as a catalysta

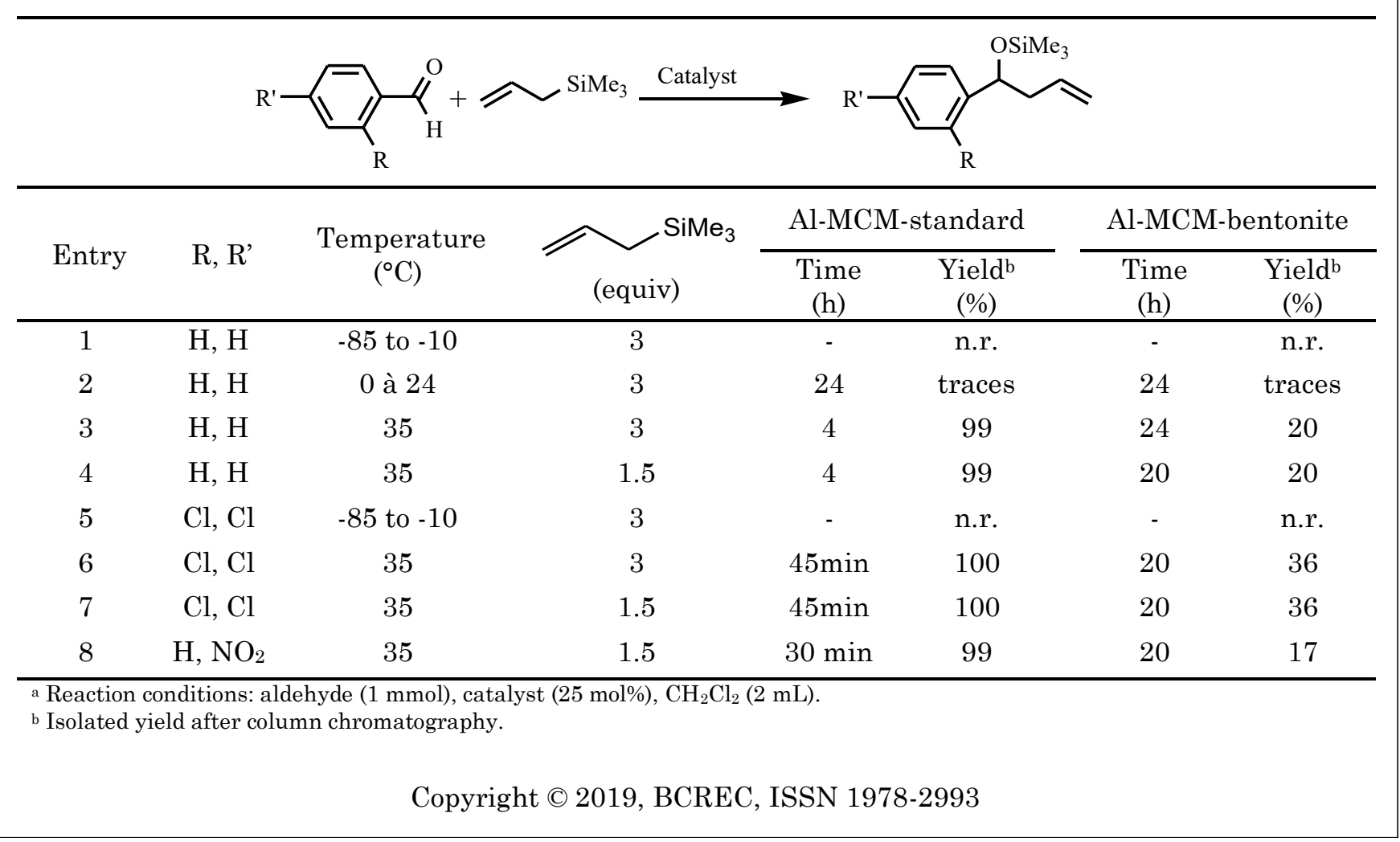


(entries 1 and 5). We have carried out several tests by increasing the reaction temperature to $35{ }^{\circ} \mathrm{C}$. If the reaction temperature was raised from 0 to $24^{\circ} \mathrm{C}$, the catalytic activity of our materials was very low and only traces of the product were obtained (entry 2), whereas at a higher temperature $\left(35^{\circ} \mathrm{C}\right)$, the best yields were obtained in the presence of Al-MCMstandard (entry 3: 99\% yield, $4 \mathrm{~h}$ reaction time and entry 6: $100 \%$ yield, 45 min reaction time). In the presence de Al-MCM-bentonite, moderate yields were noted (entry 3: $20 \%$ yield, $24 \mathrm{~h}$ reaction time and entry $6: 36 \%$ yield, $20 \mathrm{~h}$ reaction time). The reduction of the quantity of allyltrimethylsilane to 1.5 , has not an impact on the reaction yield (entries 4, 7, and 8).

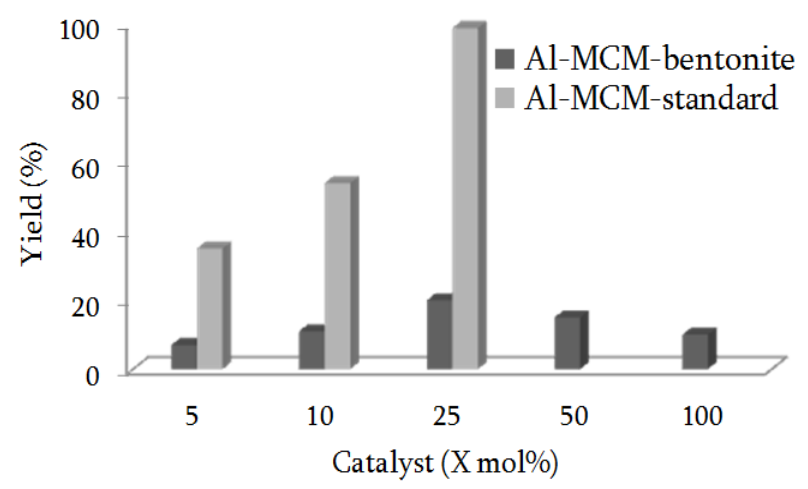

Figure 3. Effect of the amount of Al-MCMbentonite or Al-MCM-standard on the yield of the allylation reaction of benzaldehyde with allyltrimethylsilane

\subsubsection{Effect of the amount of catalyst}

In the order to understand the influence of the heterogeneous catalyst and the improvement of the yield in the presence of Al-MCMbentonite on the allylation of aromatic aldehydes with allyltrimethylsilane reaction, reactions between benzaldehyde (1 equiv) with allyltrimethylsilane (1.5 equiv) were performed using different amounts of catalyst (Table 4, Figure 3).

Using 5 mol\% (entry 1, Table 4), the AlMCM-bentonite led to a very low yield of $7 \%$ for $24 \mathrm{~h}$ reaction time, when Al-MCM-standard is used the yield is $35 \%$ for $4 \mathrm{~h}$ reaction time. We notice in Table 4 and Figure 3 that increasing the amount of catalyst has an impact on the reaction yield for Al-MCM-standard, which was not the case for Al-MCM-bentonite. Indeed, a $4 \mathrm{~h}$ reaction time led to a $54 \%$ yield using $10 \mathrm{~mol} \%$ (entry 2 , Table 5 ) and $99 \%$ yield using $25 \mathrm{~mol} \%$ of Al-MCM-standard (entry 3, Table 5). However, in the presence of Al-MCMbentonite the yield does not exceed $20 \%$ even after $20 \mathrm{~h}$ reaction time. This is confirmed by entries 4 and 5 in the Table 4 . To explain this difference in yield using these mesoporous materials Al-MCM-standard or Al-MCM-bentonite as heterogeneous catalysts, it was necessary to study the acidity of these solids.

\subsection{Evaluation of the Surface Acidity}

The Lewis acidity of the Al-MCM-standard and Al-MCM-bentonite was also evaluated by measuring the IR spectra of pyridine adsorbed on the samples, for detecting the presence and the nature of acid sites. Figure $4 \mathrm{~A}$ and $4 \mathrm{~B}$

Table 4. Allylation of benzaldehyde with allyltrimethylsilane: effect of the amount of catalystsa

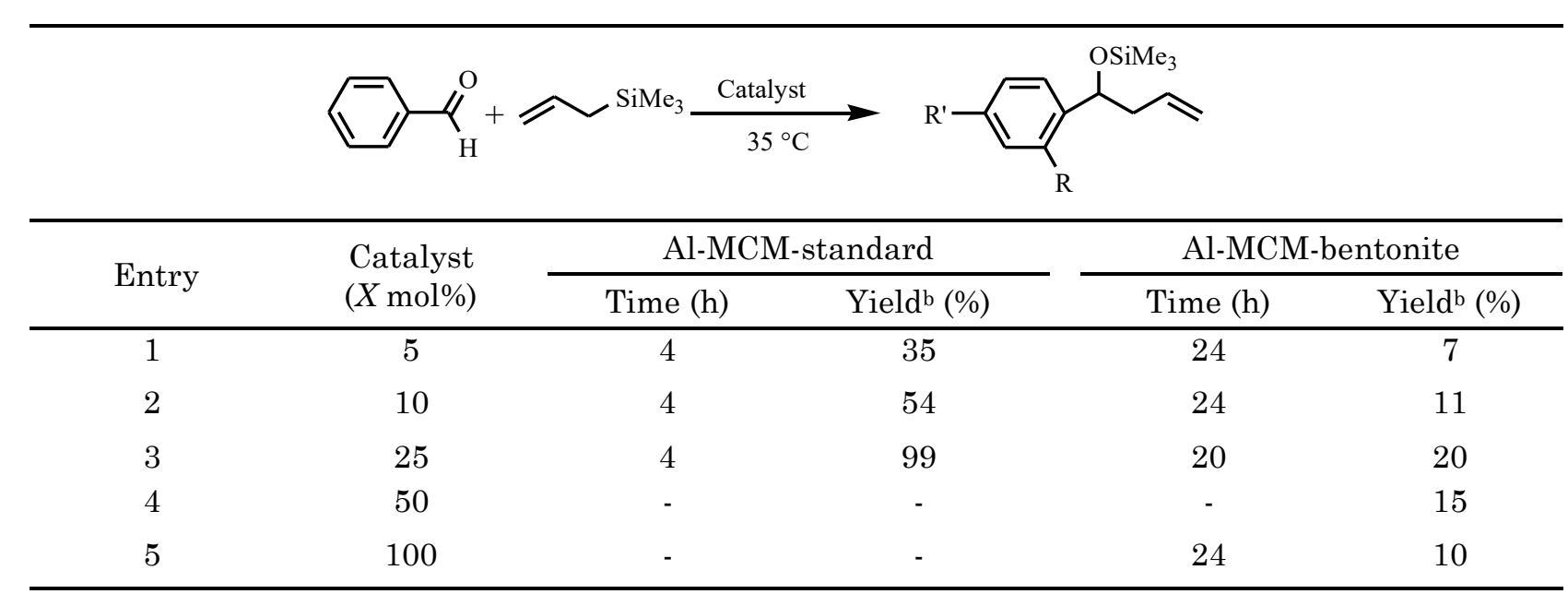

a Reaction conditions: aldehyde $(1 \mathrm{mmol})$, allyltrimethylsilane $(1.5 \mathrm{mmol}), \mathrm{CH}_{2} \mathrm{Cl}_{2}(2 \mathrm{~mL}), 35^{\circ} \mathrm{C}$.

b Isolated yield after column chromatography. 
shows the FT-IR spectra of the calcined AlMCM-bentonite and Al-MCM-standard, respectively, recorded after subsequent evacuation at $50,150,250$, and $350{ }^{\circ} \mathrm{C}$. The samples exhibit expected bands around $1450-1650 \mathrm{~cm}^{-1}$ due to the adsorbed pyridine on both Lewis and Brönsted acid sites. For Al-MCM-standard, the peaks at $1545 \mathrm{~cm}^{-1}$ and $1636 \mathrm{~cm}^{-1}$ indicate the adsorption of pyridine on Brönsted acid sites, while those at $1456 \mathrm{~cm}^{-1}$ and $1622 \mathrm{~cm}^{-1}$ attribute the adsorption of pyridine on Lewis acid sites. The peak at $1490 \mathrm{~cm}^{-1}$ can be assigned to pyridine associated with Brönsted and Lewis acid sites [38]. However, these peaks are intense and clearly distinguished, their intensity persists as the evacuation temperature is increased. This shows that Al-MCM-standard has a stable acidity even upon evacuation at $350{ }^{\circ} \mathrm{C}$. On the other hand, in the Al-MCMbentonite spectra we find the bands that characterize the presence of the acid sites, these bands have a very low intensity and it is difficult to distinguish them.

It is known that pyridine can form hydrogen bonds with the silanol groups present in the structure. Thus, for Al-MCM-bentonite, we note the appearance of new bands which correspond to silanol bonded pyridine $(\mathrm{Py}-\mathrm{H})$ at $1445 \mathrm{~cm}^{-1}$ and $1596 \mathrm{~cm}^{-1}$ [39-41]. These bands completely vanish after evacuation at $250{ }^{\circ} \mathrm{C}$.
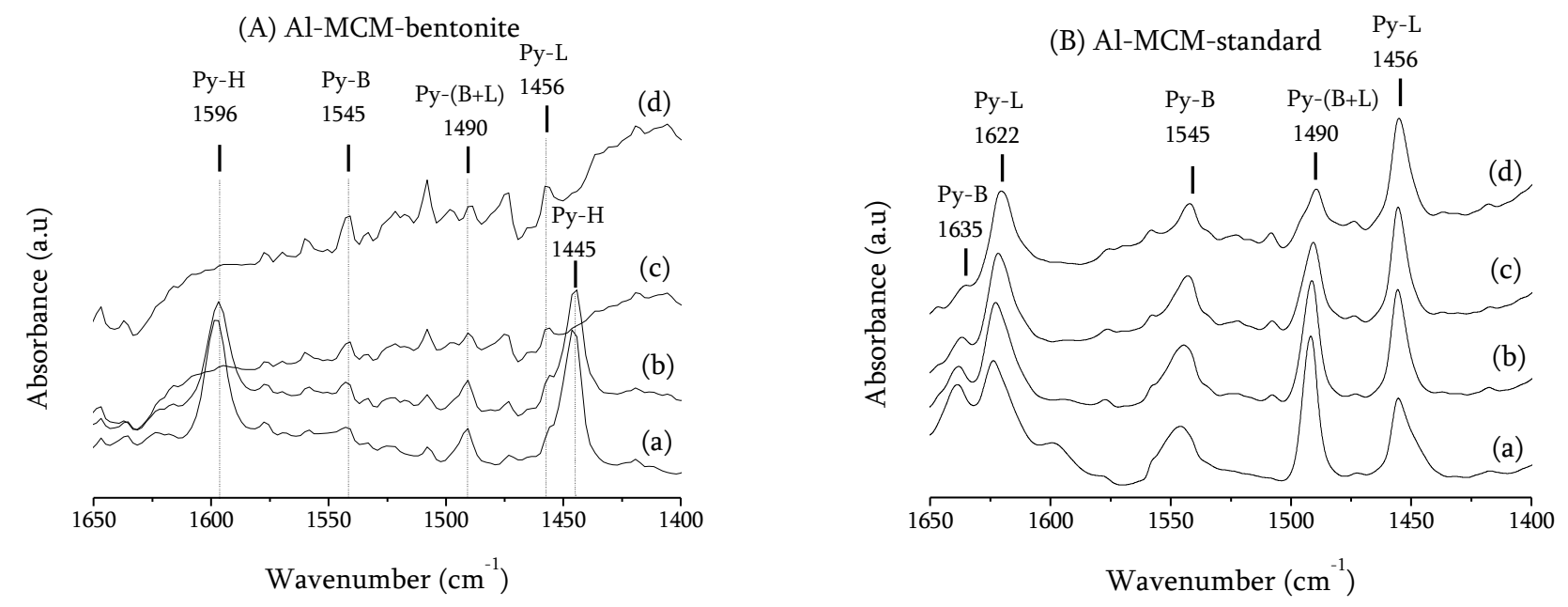

Figure 4. FTIR spectra of pyridine desorbed on calcined (A) Al-MCM-bentonite and (B) Al-MCMstandard under vacuum 3 Torr pressure at (a) $50{ }^{\circ} \mathrm{C}$, (b) $150{ }^{\circ} \mathrm{C}$, (c) $250{ }^{\circ} \mathrm{C}$, (d) $350{ }^{\circ} \mathrm{C}$

Table 5. Lewis $\left(C_{L}\right)$ and Brönsted $\left(C_{B}\right)$ acidity of the Al-MCM-bentonite and Al-MCM-standard samples measured by FTIR spectroscopy combined with pyridine adsorption and desorption at different temperatures

\begin{tabular}{ccccccc}
\hline $\begin{array}{c}\text { Acid proprieties } \\
(\text { mmol.g- })^{\mathrm{a}}\end{array}$ & Catalysts & $50{ }^{\circ} \mathrm{C}$ & $150{ }^{\circ} \mathrm{C}$ & $250{ }^{\circ} \mathrm{C}$ & $350{ }^{\circ} \mathrm{C}$ & $\begin{array}{c}\text { Total acidity } \\
(2)^{\mathrm{b}}\end{array}$ \\
\hline Total acidity $(1)^{\mathrm{a}}$ & Al-MCM-standard & 295.62 & 372.21 & 402.52 & 344.42 & 1414.77 \\
& Al-MCM- bentonite & 31.13 & 42.17 & 47.37 & 52.1 & 172.77 \\
\hline Brönsted acidity $\left(C_{B}\right)^{\mathrm{c}}$ & Al-MCM-standard & 92.13 & 124.79 & 142.78 & 85.89 & 445.59 \\
& Al-MCM- bentonite & 26.79 & 30.10 & 31.20 & 33.03 & 121.12 \\
\hline Lewis acidity $\left(C_{L}\right)^{\mathrm{c}}$ & Al-MCM-standard & 203.49 & 247.42 & 259.74 & 258.53 & 969.18 \\
& Al-MCM-bentonite & 4.34 & 12.07 & 16.17 & 19.07 & 51.65 \\
\hline$C_{L} / C_{B}$ & Al-MCM-standard & 2.21 & 1.98 & 1.82 & 3.01 & 2.17 \\
& Al-MCM-bentonite & 0.16 & 0.40 & 0.51 & 0.57 & 0.42 \\
\hline
\end{tabular}

a Total acidity (1): the sum of the concentrations $\left(\mathrm{C}_{\mathrm{L}}+\mathrm{C}_{\mathrm{B}}\right)$ at a fixed evacuation temperature.

b Total acidity (2): the sum of the total acidity (1) for different evacuation temperatures.

${ }^{c}$ To determine the concentration of both types of acid sites, the extinction coefficients [46] used were $\mathrm{e}_{\mathrm{B}}=0.73 \mathrm{~cm} \cdot \mu \cdot \mathrm{mol}{ }^{-1} \mathrm{and}$ $\mathrm{e}_{\mathrm{L}}=1.11 \mathrm{~cm} . \mu \cdot \mathrm{mol}^{-1}$, for Brönsted and Lewis acid sites, respectively. 
Lewis (Py-L) and Brönsted (Py-B) acid site concentrations were calculated by the integration of the IR bands at $1456 \mathrm{~cm}^{-1}$ and at $1545 \mathrm{~cm}^{-1}$, respectively. These concentrations were determined after evacuation of our mesoporous materials at different temperatures (Table 5).

The $C_{L} / C_{B}$ ratios show that Al-MCMstandard presents mainly Lewis acid sites. However, for Al-MCM-bentonite this ratio gives priority to Brönsted acid sites. By increasing the outgassing temperature of Al-MCMstandard to $350{ }^{\circ} \mathrm{C}$, we note that the concentration of the Lewis acid sites remains almost stable, while that of Brönsted has decreased significantly. This confirms that Al-MCM-41 pure chemicals present stronger acid sites mainly of Lewis nature. In general, the Lewis and Brönsted acid sites are attributed to tetrahedrally coordination $\mathrm{Al}$ ions into the aluminosilicate framework and their concentrations increase with the amount of aluminum incorporated $[38,42-45]$. The difference in acidity between Al-MCM-standard and Al-MCMbentonite is due to the amount of aluminum incorporated into the framework of our mesoporous materials. Effectively, according to the EDX analysis, the incorporation of aluminum in $\mathrm{Al}-\mathrm{MCM}$-standard $(\mathrm{Si} / \mathrm{Al}=13.47)$ is more important than in $\mathrm{Al}-\mathrm{MCM}$-bentonite $(\mathrm{Si} / \mathrm{Al}=$ 43.64). Kumar et al. [46] studied and compared the acidity properties of the Al-MCM- 41 prepared from coal fly ash and pure chemicals us-

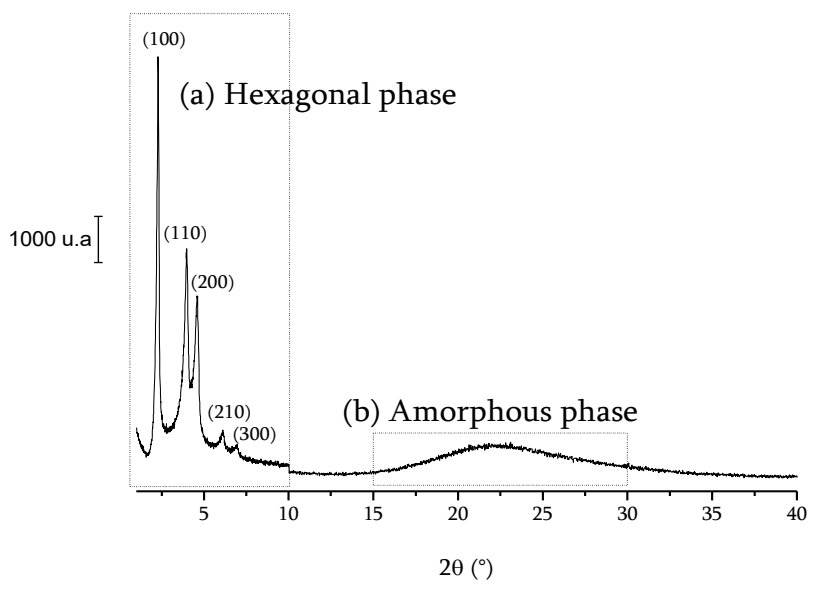

Figure 5. XRD pattern of calcined Al-MCMbentonite: (a) low angle and (b) high angle ing the cumene cracking reaction, they found that all the aluminum present in the Al-MCM41 prepared from fly ash is not catalytically active. This is due to the partial inaccessibility of the aluminum due to its incorporation in a separate aluminum phase.

To better estimate the rate of aluminum incorporated in Al-MCM-41 prepared from bentonite, it was necessary to make a difference between the $\mathrm{Si} / \mathrm{Al}$ in the amorphous part and the hexagonal part. The analysis XRD of AlMCM-bentonite in the $2 \theta$ range scanned $(2 \theta=$ $\left.1-40^{\circ}\right)$ shows that existence of amorphous phase is less important than the hexagonal phase as illustrated in Figure 5. Thus, the evaluation of the acidity of the amorphous phase could be negligible compared to the acidity of the hexagonal phase. As shown in Table 6 , the $\mathrm{Si} / \mathrm{Al}$ ratio of mesoporous material prepared from the bentonite is 13.0 for the amorphous part. This ratio is higher than the $\mathrm{Si} / \mathrm{Al}$ of natural bentonite (4.7) and close to fused bentonite (8.07). From that we can say that, the synthesis conditions and the aluminosilicate source (supernatant solution due to alkaline fusion) of the bentonite used to obtain AlMCM-bentonite does not allow to control and to incorporate of aluminum in sufficient quantity in this material, which is characterized by $\mathrm{Si} / \mathrm{Al}=44$ in the hexagonal part. This is the cause of the low acidity of Al-MCM-bentonite, which gave moderate yields using it as Lewis acid in the allylation reactions of aromatic aldehydes with allyltrimethylsilane.

\section{Conclusions}

In summary, aluminum modified mesoporous molecular sieve with MCM-41 structure was synthesized from the bentonite low-cost mass material as $\mathrm{Si}$ and $\mathrm{Al}$ source. Its Lewis acidity is compared with that of Al-MCM-41 prepared from pure chemicals reagents. The isomorphic substitution of the silicon atom by the aluminum atom decreases the structural order of Al-MCM-standard, whereas Al-MCMbentonite has better structural organization. However, this interesting structural order of Al-MCM-bentonite does not reflect its textural properties ( $S_{\text {BET }}$ of $674 \mathrm{~m}^{2} / \mathrm{g}$ and mesoporous volume of $0.42 \mathrm{~cm}^{3} / \mathrm{g}$ ), compared to those of $\mathrm{Al}$ -

Table 6. EDAX results

\begin{tabular}{ccccc}
\hline \multirow{2}{*}{ Sample } & \multirow{2}{*}{ Natural bentonite } & \multirow{2}{*}{ Fused bentonite } & \multicolumn{2}{c}{ Al-MCM-bentonite } \\
\cline { 3 - 5 } & & & Hexagonal phase & Amorphous phase \\
\hline $\mathrm{Si} / \mathrm{Al}$ & 4.76 & 8.07 & 43.64 & 12.43 \\
\hline
\end{tabular}


MCM-standard ( $S_{\text {BET }}$ of $983 \mathrm{~m}^{2} / \mathrm{g}$ and mesoporous volume of $0.76 \mathrm{~cm}^{3} / \mathrm{g}$ ).

The evaluation of Lewis acidity by the catalytic reaction of allylation of aromatic aldehydes by allylsilane showed that Al-MCMstandard gives a the best yield (99\%) after four hours reaction time, while the yield does not exceed $20 \%$ even after a reaction time of $20 \mathrm{~h}$ for Al-MCM-bentonite. The increase in the amount of the Al-MCM-bentonite catalyst to $100 \mathrm{~mol} \%$, has not improved the reaction yield. The Lewis acidity of the Al-MCM-standard and Al-MCM-bentonite was also evaluated by measuring the IR spectra of pyridine adsorbed on the samples. This analysis of these materials revealed a very low Lewis acidity on Al-MCMbentonite, whereas on Al-MCM-standard confirmed the existence of the Brönsted and Lewis acid sites. Concentrations of these sites have given priority to Lewis acid sites. The difference in acidity between Al-MCM-41 standard and MCM-bentonite is due to the amount of aluminum incorporated into the framework of our mesoporous materials. Effectively, according to the EDX analysis, the incorporation of aluminum in Al-MCM-41 standard $(\mathrm{Si} / \mathrm{Al}=$ 13.47) is more important than in Al-MCMbentonite $(\mathrm{Si} / \mathrm{Al}=43.64)$.

\section{Acknowledgments}

The authors are very grateful to the Laboratory of Catalysis and Synthesis in Organic Chemistry (LCSCO), faculty of Science - Abu Bakr Belkaid University of Tlemcen (Algeria).

\section{References}

[1] Mayr, H., Gorath, G. (1995). Kinetics of the Reactions of Carboxonium Ions and Aldehyde Boron Trihalide Complexes with Alkenes and Allylsilanes. Journal of the American Chemical Society, 117: 7862-7868.

[2] Aggarwal, V.K, Vennall, G.P. (1996). Scandium trifluoromethanesulfonate, a novel catalyst for the addition of allyltrimethylsilane to aldehydes. Tetrahedron Letters, 37: 37453746.

[3] Zhang, W.C., Viswanathan, G.S., Li, C.J. (1999). Scandium triflate catalyzed in situ Prins-type cyclization: formations of 4tetrahydropyranols and ethers. Chemical Communications, 291-292.

[4] Fang, X., Watkin, J.G., Warner, B.P. (2000). Ytterbium trichloride-catalyzed allylation of aldehydes with allyltrimethylsilane. Tetrahedron Letters, 41: 447-449.
[5] Watahiki, T., Oriyama, T. (2002). Iron (III) chloride-catalyzed effective allylation reactions of aldehydes with allyltrimethylsilane. Tetrahedron Letters, 43: 8959-8962.

[6] Durand, A.C., Brahmi, L., Lahrech, M., Hacini, S., Santelli, M. (2005). Preparation of 4-Arylcyclopentenes by Sequential Diallylation of Arylaldehydes and Ring-Closing Metathesis. Synthetic Communications, 35: 1825-1833.

[7] Brahmi, L., Ali-Dahmane, T., Hamacha, R., Hacini, S. (2016). Catalytic Performance of Al-MCM-41 Catalyst for the Allylation of Aromatic Aldehydes with Allyltrimethylsilane: Comparison with $\mathrm{TiCl}_{4}$ as Lewis acid. Journal of Molecular Catalysis A: Chemical, 423: 31-40.

[8] Beck, J.S., Vartuli, J.C., Roth, W.J., Leonowicz, M.E., Kresge, C.T., Schmitt, K.D., Chu, C.T.W., Olson, D.H., Sheppard, E.W., McCullen, S.B., Higgins, J.B., Schlenkert, J.L. (1992). A new family of mesoporous molecular sieves prepared with liquid crystal templates. Journal of the American Chemical Society, 114: 10834-10843.

[9] Kresge, C.T., Leonowicz, M.E., Roth, W.J., Vartuli, J.C., Beck, J. (1992). Ordered mesoporous molecular sieves synthesized by a liquid-crystal template mechanism. Nature, 359: 710-712.

[10] Cestors, Y., Haller, G.L. (2001). Several factors affecting Al-MCM-41 synthesis. $\mathrm{Mi}$ croporous and Mesoporous Materials, 43: 171179.

[11] Shylesh, S., Singh, A.P. (2005). Vanadiumcontaining ordered mesoporous silicates: Does the silica source really affect the catalytic activity, structural stability, and nature of vanadium sites in V-MCM-41. Journal of Catalysis, 233: 359-371.

[12] Gallo, R., Pastore, O., Schuchardt, U. (2008). Study of the effect of the base, the silica and the niobium sources on the [Nb]-MCM-41 synthesized at room temperature. Journal of Non-Crystalline Solids, 354: 1648-1653.

[13] Fontes, M.S.B., Melo, D.M.A., Costa, C.C., Braga, R.M., Melo, M.A.F., Alves, J.A.B., Silva, M.L.P. (2016). Effect of different silica sources on textural parameters of molecular sieve MCM-41. Ceramica, 62: 85-90.

[14] Ali-Dahmane, T., Brahmi, L., Hamacha, R., Benguddach, A. (2017). How to control the structural properties of purely siliceous MCM-41. Annales de Chimie Sciences des Matériaux, 40: 149-163.

[15] Xie, Y.L., Zhang, Y., Ouyang, J., Yang, H.M. (2014). Mesoporous material Al-MCM-41 from natural halloysite. Physics and Chemistry of Minerals, 41: 497-503. 
[16] Yu, Z.H., Wang, Y., Liu, X.Y., Sun, J.B., Sha, G.Y., Yang, J.H., Meng, C.G.A. (2014). A novel pathway for the synthesis of ordered mesoporous silica from diatomite. Materials Letters, 119: 150-153.

[17] Du, C.F., Yang, H.M. (2012). Investigation of the physicochemical aspects from natural kaolin to Al-MCM-41 mesoporous materials. Journal of Colloid Interface Science, 369: 216222 .

[18] Yang, H., Deng, Y., Du, C., Jin, S. (2010). Novel synthesis of ordered mesoporous materials Al-MCM-41 from bentonite. Applied Clay Science, 47: 351-355.

[19] Ali-Dahmane, T., Adjdir, M., Hamacha, R., Villieras, F., Bengueddach, A., Weidler, P.G. (2014). The synthesis of MCM-41 nanomaterial from Algerian Bentonite: The effect of the mineral phase contents of clay on the structure properties of MCM-41. Comptes Rendus Chimie, 17: 1-6.

[20] Chang, H.L., Chun, C.M., Aksay, I.A., Shih, W.H. (1999). Conversion of Fly Ash into Mesoporous Aluminosilicate. Industrial \& Enggineering Chemistry Research, 38: 973-977.

[21] Chandrasekar, G., You, K.S., Ahn, J.W., Ahn, W.S. (2008) Synthesis of hexagonal and cubic mesoporous silica using power plant bottom ash. Microporous and Mesoporous Materials, 111: 455-462.

[22] Liu, Z.S., Li, W.K., Huang, C.Y. (2014). Synthesis of mesoporous silica materials from municipal solid waste incinerator bottom ash. Waste Management, 34: 893-900.

[23] Yang, G., Deng, Y.X., Ding, H., Lin, Z.X., Shao, Y.K., Wang, Y. (2015). A facile approach to synthesize MCM-41 mesoporous materials from iron ore tailing: Influence of the synthesis conditions on the structural properties. Applied Clay Science, 111: 61-66.

[24] Fu, P.F., Yang, T.W., Feng, J., Yang, H.F. (2015). Synthesis of mesoporous silica MCM41 using sodium silicate derived from copper ore tailings with an alkaline molted-salt method. Journal of Industrial and Engineering Chemistry, 29: 338-343.

[25] Lin, L.Y., Bai, H. (2013). Efficient Method for Recycling Silica Materials from Waste Powder of the Photonic Industry. Environmental Science \& Technology, 47:4636-4643.

[26] Lin, L.Y., Kuo, J.T., Bai, H. (2011). Silica materials recovered from photonic industrial waste powder: its extraction, modification, characterization and application. Journal of Hazardous Materials, 192: 255-262.

[27] Liou, T.H. (2011). A green route to preparation of MCM-41 silicas with well-ordered mesostructure controlled in acidic and alka- line environments. Chemical Engineering Journal, 171: 1458-1468.

[28] Wang, W.X., Martin, J.C., Fan, X.T., Han, A.J., Luo, Z.P., Sun, L.Y. (2012). Silica Nanoparticles and Frameworks from Rice Husk Biomass. ACS Applied Materials \& Interfaces, 4: 977-981.

[29] Zeng, W.T., Bai, H. (2014). Swelling-agentfree synthesis of rice husk derived silica materials with large mesopores for efficient $\mathrm{CO}_{2}$ capture. Chemical Engineering Journal, 251: 1-9.

[30] Ghorbani, F., Younesi, H., Mehraban, Z., Çelik, M.S., Ghoreyshi, A.A., Anbia, M.J. (2013). Preparation and characterization of highly pure silica from sedge as agricultural waste and its utilization in the synthesis of mesoporous silica MCM-41. Journal of the Taiwan Institute of Chemical Engineers, 44: 821-828.

[31] Dodson, J.R., Cooper, E.C., Hunt, A.J., Matharu, A., Cole, J., Minihan, A., Clark, J.H., Macquarrie, D.J. (2013). Alkali silicates and structured mesoporous silicas from biomass power station wastes: the emergence of bio-MCMs. Green Chemistry, 15: 1203-1210.

[32] Adjdir, M., Ali-Dahmane, T., Weidler, P.G., Friedrich, F., Scherer, T. (2009). The synthesis of Al-MCM-41 from volclay-A low-cost Al and Si source. Applied Clay Science, 46: 185189.

[33] Adjdir, M., Ali-Dahmane, T., Weidler, P.G. (2009). The structural comparison between Al-MCM-41 and B-MCM-41. Comptes Rendus Chimie, 12: 793-800.

[34] Brunauer, S., Emmett, P.H., Teller, E.J. (1938). Adsorption of Gases in Multimolecular layers. Journal of the American Chemical Society, 60: 309-319.

[35] Talha, Z., Bachir, C., Bellahouel, S.Z.S., Bengueddach, A., Villiéras, F., Pelletier, M., Weidler, P.G., Hamacha, R. (2017). Al-Rich Ordered Mesoporous Silica SBA-15 Materials: Synthesis, Surface Characterization and Acid Properties. Catalysis Letters, 147(8): 2116 - 2126.

[36] Hui, K.S., Chao, C.Y.H. (2006). Synthesis of MCM-41 from coal fly ash by a green approach: Influence of synthesis $\mathrm{pH}$. Journal of Hazardous Materials, 137: 1135-1148.

[37] Campos, J.M., Lourenco, J.P., Fernandes, A., Ribeiro, M.R. (2008). Mesoporous Ga-MCM41: A very efficient support for the heterogenisation of metallocene catalysts. Catalysis Communications, 10: 71-73.

[38] Araujo, R.S., Azevedo, D.C.S., Cavalcante, C.L., Jimenez-Lopez, A., Rodriguez-Castellon, E. (2008). Adsorption of polycyclic aromatic 
hydrocarbons (PAHs) from isooctane solutions by mesoporous molecular sieves: Influence of the surface acidity. Microporous and Mesoporous Materials, 108: 213-222.

[39] Jentys, A., Kleestorfer, K., Vinek, H. (1999). Concentration of surface hydroxyl groups on MCM-41. Microporous and Mesoporous Materials, 27: 321-328.

[40] Conesa, T.D., Hidalgo, J.M., Luque, R., Campelo, J.M., Romero, A.A. (2006). Influence of the acid-base properties in Si-MCM-41 and B-MCM-41 mesoporous materials on the activity and selectivity of $\varepsilon$-caprolactam synthesis. Applied Catalysis A, 299: 224-234.

[41] Chanquiia, C., Andrini, L., Fernandez, J., Crivello, M., Requejo, F., Herrero, E.R., Eimer, G.A. (2010). Influence of the synthesis conditions on the physicochemical properties and acidity of Al-MCM-41 as catalysts for the cyclohexanone oxime rearrangement. The Journal of Physical Chemistry, 114: 1222112229 .

[42] Aguado, J., Serrano, D.P., Escola, J.M. (2000). A sol-gel approach for the room temperature synthesis of Al-containing micelle-templated silica. Microporous and Mesoporous Materials, 34: 43-54.
[43] Sang, Y., Li, H., Zhu, M., Ma, K., Jiao, Q., $\mathrm{Wu}, \mathrm{Q}$. (2013). Catalytic performance of metal ion doped MCM-41 for methanol dehydration to dimethyl ether. Journal of Porous Materials, 20: 1509-1518.

[44] Vaschetto, E.G., Pecchi, G.A., Casuscelli, S.G., Eimer, G.A. (2014). Nature of the active sites in Al-MCM-41 nano-structured catalysts for the selective rearrangement of cyclohexanone oxime toward $\varepsilon$-caprolactam. $\mathrm{Mi}$ croporous and Mesoporous Materials, 200: 110-116.

[45] Morales, I.J., Recio, M.M., Gonzalez, J.S., Torres, P.M., Lopez, A.J. (2015). Production of 5-hydroxymethylfurfural from glucose using aluminium doped MCM-41 silica as acid catalyst. Applied Catalysis B: Environmental, 164: 70-76.

[46] Kumar, P., Mal, N., Oumi, Y., Yamana, K., Sano, T. (2001). Mesoporous materials prepared using coal fly ash as the silicon and aluminium source. Journal of Materials Chemistry, 11: 3285-3290. 